\title{
El EUfEMismo COMO INSTRUMENTO DE MANIPULACIÓN EN LA PRENSA ESCRITA
}

\author{
Ana Trujillo Garrido \\ Universidad DE Murcia \\ ana.trujillo@um.es
}

\begin{abstract}
Resumen: El presente trabajo tiene como objeto el eufemismo y el uso manipulador que la prensa escrita hace de él. Surge la necesidad de seguir haciendo hincapié en este tipo de usos malintencionados del lenguaje, de modo que la sociedad pueda mantenerse alerta en todo momento ante tal situación. Para dar cuenta de la realidad que aquí referimos, se ha realizado un corpus de eufemismos recogidos de la prensa española del siglo XXI (2000 hasta la actualidad). Tras su análisis, que ha seguido la metodología del análisis del discurso y análisis crítico del discurso, ha quedado de manifiesto que la prensa escrita hace uso de eufemismos con fines manipulativos (tanto de la realidad referida, como del referente, como del individuo). Además, no solo reproduce los eufemismos llegados a ella desde los distintos ámbitos de la sociedad, sino que los mantiene y perpetúa, convirtiéndolos en propios.
\end{abstract}

Palabras clave: Eufemismo, manipulación lingüística, prensa escrita

Abstract: This work has the euphemism as object and the manipulative use that the written press makes of it. Appear the necessity to continue emphasizing this type of malicious uses of language so that society can be alert at all times to the situation. To give an account of the reality there has made a corpus of euphemisms collected from the Spanish press of the 21 st century (2000 to the present). After their analysis, which has followed the methodology of analysis of discourse and critical analysis of the discourse, it has become clear that the written press makes use of euphemisms with manipulative fines (reality of reference, the referent and the individual). Moreover, not only reproduces the euphemisms that came to it from the different spheres of society, but also maintains and perpetuates them.

Keywords: Euphemism, linguistic manipu-

lation, written press 


\section{INTRODUCCIÓN}

El presente trabajo pretende ser un acercamiento al concepto de eufemismo y a su vertiente como posible recurso manipulativo en los medios de comunicación. Ante tal objeto de estudio, cabe la pregunta de por qué decantarse por el análisis de un recurso tan ampliamente tratado, no solo desde el ámbito lingüístico, sino desde todo tipo de disciplinas como la psicología, la sociología o la etnografía. La justificación la hallamos, precisamente, en esa posible vertiente manipulativa recogida a lo largo del trabajo. Necesarios siguen siendo estudios que pongan el foco de atención en la manipulación que se puede llevar a cabo a través de las palabras y los discursos, pues el material lingüístico, conformado en el discurso y sumado a factores cognitivos y sociales, sustenta la construcción de la vida en sociedad. Así las cosas, se hace necesario seguir analizando este tipo de realidades que, utilizadas malintencionadamente, pueden dar lugar a una triple manipulación: del referente, de la realidad y del individuo. Análisis que, del mismo modo que señalan la situación de manipulación, ayudan a mantener al receptor alerta ante posibles prevaricaciones lingüísticas.

El objetivo de este trabajo, por tanto, ha sido determinar, mediante el análisis de un corpus - que no incorporamos íntegro al artículo por evidentes razones de formato y economía-, si ciertos eufemismos contribuyen a la manipulación lingüística y al oscurecimiento del sentido de las noticias, afectando así a la comprensión e interpretación de las mismas por parte del receptor. No obstante, en primer lugar, antes de proceder al análisis de datos, debemos realizar precisiones teóricas a cerca de los conceptos tratados, a saber, manipulación y eufemismo.

\subsection{El concepto de manipulación}

Por lo que respecta a la primera de las realidades aludidas, definirla requiere referirse, en primer lugar, al concepto de discurso, de naturaleza social. Se trata de una forma de acción entre personas que se da a partir del uso lingüístico contextualizado, bien oral, bien escrito (Calsamiglia y Tusón, 2012). La lengua se presenta como la materia prima del discurso, y en este sentido, en tanto que esta ofrece una serie de opciones de entre las que podemos seleccionar, el discurso supondrá una elección (fónica, gráfica, morfosintáctica o léxica) mediante la que se dará la interacción discursiva. Además, las distintas piezas textuales a las que dan lugar los discursos tienen, necesariamente, unos fines y un contexto lingǘstico, local, cognitivo y sociocultural.

Dicho lo cual, la elección lingüística (convertida en ocasiones en estrategia) se realizará de acuerdo a parámetros contextuales tales como la situación comunicativa o los propósitos de quien realiza el discurso. Esos propósitos conllevarán, asimis- 
mo, un proceso interpretativo de intenciones por parte de quien recibe el discurso (enunciatario). Es en ese marco, concretamente asociado a los propósitos de quien realiza el discurso, donde encontramos el fenómeno de la manipulación.

Seco (2002) apunta tres sentidos sobre el verbo manipular, y es el tercero de ellos el que aquí nos atañe: «manipular puede ser operar o actuar sobre algo desvirtuando su auténtico sentido de manera hábil y con un fin interesado» (Seco, 2002: 7). En este caso, ese «algo» serían las palabras, por lo que la manipulación de estas sería el proceso por el cual «se somete a las palabras desvirtuando su sentido auténtico y poniéndolas al servicio de intereses concretos» (Seco, 2002: 8). Fuentes y Alcaide (2007) dirán que la manipulación nace de la violación a la máxima de la calidad de Grice, aquella que hace alusión a la sinceridad de las contribuciones del emisor. Cuando dicha sinceridad no aparece en el discurso, o bien está encubierta, aparece la manipulación.

\subsection{El concepto de eufemismo}

En cuanto al eufemismo, la palabra tiene su origen etimológico en el mundo helénico (procede del griego euphemismós, que deriva, a su vez, de euphemos, cuyo significado es «que habla bien, que emite palabras de buen augurio» (Benveniste, 1979: 308)). En otras fuentes podemos encontrarlo con una ligera variación en el significado: «que habla bien, que evita las palabras de mal agüero» (Coromines y Pascual, 2012: s.v. hablar). El propio Benveniste (1979: 308) señala esa doble vertiente de significación que se le ha dado a la palabra: la positiva («palabras de buen augurio») y la negativa («palabras de mal augurio»), concluyendo que el verbo euphemein tiene solo la significación positiva. Zumthor (1953), sin embargo, no se detiene en las mismas consideraciones lingüísticas que recoge Benveniste, sino que pone el punto de atención en el vínculo entre la evolución semántica de la palabra y el desarrollo cultural de la sociedad. Esto es, en la naturaleza marcadamente social del eufemismo.

Por lo que respecta a las definiciones de dicho fenómeno, muchas y de naturaleza muy variada son las que se han dado a lo largo de los años. Nos encontramos, fundamentalmente, ante dos grandes grupos: las definiciones extralingüísticas y las lingüísticas. Las primeras se refieren, por lo general, al aspecto psicológico, presentando así las causas que producen el eufemismo (Hatzfeld (cit. por Montero, 1981: 24), Kronasser (cit. por Senabre, 1971: 180), Du Marsais (cit. por Munteano, 1953: 154), Kany (cit. por Casas, 1986: 33-34) o Lázaro Carreter (1974: 177)). En contraposición con la abundancia de definiciones extralingüísticas que existen acerca del eufemismo, las lingüísticas son menos. Destacamos las de Bruneau (1952), Senabre (1971), Montero (1981) o Casas (1986). A nuestro parecer, es este último quien 
propone la definición más completa del eufemismo:

A nivel de sistema, podríamos definir el eufemismo como el proceso lingüístico que, a través de unos mecanismos asociativos de orden formal o semántico, logra como resultado una neutralización léxica del vocablo interdicto. Pero esta definición sería insuficiente, al no dar entrada en ella a su rasgo esencial, su relatividad, la cual demuestra, a todas luces, que el eufemismo es, ante todo y por excelencia, un hecho social. Esto me induce a considerar el fenómeno como un acto de habla, como la actualización discursiva por parte del hablante de unos sustitutos léxicos - habituales o lexicalizados u ocasionales o creativos- que, a través de un conjunto de recursos lingüísticos y paralingüísticos, permiten, en un contexto y situación pragmática determinada, neutralizar léxicamente el término interdicto (Casas, 1986: 35-36).

De acuerdo con esta definición y con el hecho de que el eufemismo sea un fenómeno social y relativo, la interdicción, los objetos sobre los que recae e incluso el sustituto eufemístico presentan diferencias relevantes en relación a la época, el lugar e incluso el sexo de los hablantes y su formación. Así, desde una perspectiva diacrónica, incluso dentro de una misma comunidad, el eufemismo y las causas de este varían con el paso del tiempo. Cada período posee sus propias exigencias eufemísticas, derivadas de las necesidades del entorno sociocultural, por lo que forzosamente serán diferentes a las de anteriores y posteriores períodos. Esta relatividad también temporal del eufemismo engloba, como hemos dicho, a los temas que están sometidos a interdicción y a la actitud psicológica que motiva los cambios.

A esta problemática se le debe hacer frente con ayuda del contexto y la situación, de manera que se pueda determinar si una metáfora concreta, metonimia o deformación fonética es eufemística o no. Llegaría así Montero (1981) a la conclusión de que no existen palabras-eufemismos ni recursos lingüísticos que sean eufemismos per se, sino que existen los usos eufemísticos: «una palabra puede no ser sentida como eufemismo a determinado nivel y sí serlo en su ambiente de origen, o, al revés, un término, por ejemplo, un tecnicismo, puede no tener un uso eufemístico en su contexto de origen y, sin embargo, admitirse como tal fuera de él» (Montero, 1981: 36). Del mismo modo, Senabre (1971: 179) dirá: «no se puede afirmar que una palabra sea un sustituto eufemístico, sino que, en un contexto dado, tiene un uso eufemístico. Por eso el eufemismo no pertenece, aprovechando los términos saussureanos, a la lengua, al sistema, sino al habla $\gg$. Por tanto, la característica de la inestabilidad propicia que cualquier término sujeto a interdicción pueda albergar usos eufemísticos, momentáneamente inventados por los hablantes y que no tienen 
por qué tener continuidad temporal.

\subsection{El eufemismo como recurso manipulador}

Una vez presentado el concepto de eufemismo, debemos centrarnos en dicho fenómeno como instrumento de manipulación social, más concretamente en el utilizado en la prensa escrita. Según Gallud (2005), en el pasado las funciones del eufemismo respondían a una necesidad perfeccionista y estética de la lengua por parte de los hablantes. Dicho recurso eliminaba del habla malsonancias o voces groseras o molestas, del mismo modo que permitía no pronunciar palabras tabú y tenía una aplicación moralista. Hoy en día, en cambio, la realidad socio-lingüística a la que nos enfrentamos en el caso del eufemismo es muy distinta de la anteriormente señalada: se ha producido un cambio de paradigma con respecto al eufemismo, pues el de convivencia social ha sido sustituido, en gran media, por el que se presenta con capacidad manipulativa.

Afirma Gallud (2005) que el uso del eufemismo para evitar el tabú se ha reducido de manera drástica, como ya mantuvieran Casas (1986) o Montero (1981) años antes. Tanto es así que el procedimiento contrario, el disfemístico, es común en la actualidad. El eufemístico, en cambio, se ha extendido en campos referidos al desarrollo y al mundo moderno, como el que se produce por influjo publicitario de marcas comerciales o por imitación cultural ('marketing' en lugar de 'marcadotécnia', por ejemplo). Ahora bien, lo que se nos presenta como una realidad verdaderamente grave es la utilización del eufemismo como instrumento manipulativo de cambio social.

Sostiene Gallud (2005: 122) que dicha realidad se hace evidente «en un alto número de casos originados por motivaciones sociales o clasistas o bien directamente causados para facilitar fines políticos o económicos específicos». Esta circunstancia lleva a Gallud (2005: 122) a elaborar una propia definición de eufemismo más precisa y acorde con los usos actuales de dicho recurso: «Los eufemismos son nociones adulteradas que tienden a edulcorar la realidad y a favorecer a los más diversos intereses». En esta definición, además de otros factores, entra en juego la responsabilidad de los comunicadores ante sus lectores, cuestión de polémica. Autores como Grijelmo (2008) sostienen que los periodistas no son responsables de la manipulación que muchas veces se lleva a cabo desde la prensa escrita, sino simples instrumentos: los periodistas trasladarían

${ }^{1}$ Esta idea, la de que el eufemismo puede no ser solo léxico, la rebate Albelda (2010: 344), por ejemplo, al afirmar que «Mientras que la atenuación es un mecanismo del que puede participar cualquier unidad lingüística en todos los niveles (entonativo, morfológico, sintáctico, etc.), el eufemismo es el resultado concreto de un proceso de sustitución léxica». 
Al pie de la letra el lenguaje de los políticos, los economistas, los sindicatos, los terroristas [...]. Los periodistas han sucumbido, han perdido el poder de dar nombre a las cosas y han entrado en el juego de quienes pretendieron edulcorar la realidad para ajustarla mejor a sus intereses (Grijelmo, 2008: 528-529).

Así, los periodistas utilizarían términos inventados realmente por políticos, economistas, sindicalistas, jueces, etc. con tal de mantenerse fieles a la cita original, pues son, en definitiva, agentes mediáticos, que se hallan en una situación comprometida, pues se deben a sus fuentes y lectores. Gallud (2005), sin embargo, aunque no los señala como culpables directos, sí afirma que son los comunicadores quienes tienen la oportunidad, desde sus medios, para desechar términos eufemísticos bajo los que se pretende la manipulación y sustituirlos por términos veraces. El hecho de que no lo hagan, sostiene, sí es, definitivamente, reprobable. En esta misma línea, encontramos en el Libro de estilo de El País (El País, 2002: 2.3) la siguiente afirmación: «Los periodistas deben cuidar de llamar a las cosas por su nombre, sin caer en los eufemismos impuestos por determinados colectivos»; o en el Libro de estilo de $A B C$, la siguiente: «evítense eufemismos innecesarios» (2001: 163). Son estas frases las que resumen a la perfección lo que la teoría periodística sostiene sobre la utilización de términos eufemísticos.

Así, desde un punto de vista normativo, en la información periodística se debe utilizar un estilo «tendente a la pura denotación» (Lázaro Carreter, 1990: 28) que refleje con exactitud lo que la noticia quiere contar y con la suficiente claridad, rasgo requerido a los textos de carácter periodístico.

Si atendemos, por otra parte, a la división del eufemismo, F. Rodríguez (1991: 44-64), fijándose en el lenguaje político para su estudio, lo ha clasificado del siguiente modo, atendiendo a su naturaleza:

1. Léxica: se da en el caso de la sustitución de un vocablo por otro, por ejemplo neutralizar por matar.

2. Gramatical, donde se distinguen dos aspectos:

2.1. Nominalizaciones: ha habido una descarga nuclear, donde lo que se

2 Ese «disfrazar la realidad» tiene mucho que ver con uno de los principales problemas que plantea el eufemismo: el de la reducción de la claridad informativa cuando aparece y, por tanto, la posible incomprensión por parte del lector. Aunque el emisor pretenda que el sustituto eufemístico sea el equivalente sinonímico al término interdicto, no queda garantizado que el receptor lo vaya a interpretar de manera correcta. El margen interpretativo de los eufemismos, por tanto, es amplio debido a sus características propias (Albelda, 2010: 362) y, como hemos señalado, libros de estilo y autoridades lingüísticas advierten de que su uso puede constituir un obstáculo en la comunicación. 
intenta es atenuar el papel del agente y de las víctimas.

2.2. Construcciones pasivas: con el mismo objetivo que las anteriores. Se busca, además, un distanciamiento con respecto a la acción.

3. Presuposiciones, sugerencias: es el caso del ejemplo “¿Por qué la OTAN necesita armas nucleares?". Mediante esa pregunta estamos ya presuponiendo que dicha organización necesita esas armas.

Como vemos, además del eufemismo léxico, existen otros recursos a la hora de disfrazar la realidad o querer distorsionarla ${ }^{1}$. A los anteriores, añade Núñez (2001) los de restar importancia a un hecho, aceptar un hecho negativo para poder llegar así a conseguir un bien mayor o utilizar, directamente, el eufemismo y el término interdicto, explicando que no se trata de [término interdicto], sino de [eufemismo]. Quedaría así de manifiesto, según Núñez (2001: 427), que «Lo que subyace, por tanto, es la idea wittgensteniana de que el lenguaje disfraza el pensamiento (nosotros podemos ir un poco más lejos: creemos que el lenguaje también pretende disfrazar la realidad) $\gg^{2}$. Muchos otros, además, son los autores que han realizado afirmaciones similares en relación con el eufemismo y la manipulación. Así: «Los sustitutos eufemísticos conllevan una percepción concreta de la realidad que puede influir en la percepción del receptor y, por tanto, filtrar su pensamiento» (Guitart, 2005: 271). Por su parte, Grijelmo (2008) añadirá:

Quien logra dar nombre a una idea, empieza ya a dominarla. Es éste un principio que conocen bien los grupos económicos, jurídicos, sociales o políticos [...] El lenguaje de los medios de comunicación está repleto ya de nociones adulteradas que tienden a edulcorar la realidad y a favorecer los más diversos intereses (Grijelmo, 2008: 528-529).

Pese a estas afirmaciones, ciertas todas ellas, no debemos dejar de tener en cuenta que

La filtración del pensamiento, la influencia de los medios de comunicación a través del uso del lenguaje o el deseo de cambiar la realidad mediante las palabras son consecuencias perseguidas cuando se emplea el eufemismo, pero también, desde luego, forman parte del poder que en sí posee el lenguaje como instrumento de comunicación (Albelda, 2010: 361).

\footnotetext{
${ }^{3}$ De Benito, E. (13 de diciembre, 2010). Primer descenso del número de abortos en una década. El País. Recuperado de https://elpais.com/sociedad/2010/12/13/actualidad/1292194802_850215. html
} 


\section{DATOS}

La recogida de datos que conforman el corpus anteriormente referido tuvo lugar entre los meses de febrero y junio de 2017, aunque en enero de 2018 se procedió, de nuevo, a la comprobación de los enlaces de direcciones webs de cada una de las noticias incorporadas. El campo de búsqueda ha sido, fundamentalmente, la prensa escrita en lengua española, preferiblemente de España, prestando especial atención a los tres periódicos de tirada nacional más importantes del país: El País, $A B C$ y El Mundo (existen, no obstante, tres excepciones: una noticia de la BBC, otra del Diario de Sevilla y una última de Expansión, pues nos parecían tres ejemplos relevantes fuera de los tres diarios principales de análisis). La búsqueda se ha realizado de manera manual, sirviéndonos de motores de búsqueda como Google o de motores de búsqueda propios, internos, de los diarios. Por lo que respecta a los límites temporales, no se han querido rebasar los umbrales del siglo XXI, por lo que los eufemismos recogidos están presentes en noticias desde el año 2000 hasta la actualidad (tres noticias de 2008, una de 2009, una de 2010, una de 2012, dos de 2014 , una de 2015, tres de 2016 y cuatro de 2017). De este modo, según nuestra opinión, se ofrecía un panorama real del estado del eufemismo como recurso manipulativo en nuestros días.

Por lo que respecta a la división del corpus de eufemismos, este ha quedado clasificado en cuatro grupos: eufemismos sociales, eufemismos referidos a la violencia, eufemismos económicos y eufemismos políticos, por ser estas las temáticas donde más incidencia se ha visto de los procesos eufemísticos con fines manipulativos. Dentro de cada uno de los grupos encontraremos, a su vez, subdivisiones temáticas más concretas, que especificaremos en los epígrafes. Así las cosas, el corpus de eufemismos queda como sigue:

\section{ANÁLISIS DE RESULTADOS}

\section{Eufemismos sociales}

\subsection{Interrupción voluntaria del embarazo}

En muchas ocasiones, el término aborto se ha visto arrinconado por la cantidad de connotaciones que puede acarrear, no siempre positivas para todos los hablantes. Su sustituto, interrupción voluntaria del embarazo, ha llegado incluso a convertirse en un acrónimo, utilizándose IVE para hacer referencia a dicha realidad. Así lo vemos en el siguiente ejemplo del diario El País ${ }^{3}$, concretamente en la bajada del titular: «En 2009 se practicaron 111.482 interrupciones, un 3,7\% menos que en 
2008», donde incluso se decide omitir voluntarias del embarazo tras interrupciones. En la primera frase del cuerpo de la noticia volvemos a encontrar el eufemismo: «En 2009 se practicaron en España 111.482 interrupciones voluntarias del embarazo, un $3,7 \%$ menos que las 115.812 de 2008», y más adelante, también en el cuerpo, la noticia se vuelve a hacer eco de la expresión, no ya por cuenta propia, sino citando al ministerio como usador de dicho eufemismo: «El ministerio destaca que la tasa de interrupciones del embarazo por mil mujeres de entre 15 y 45 años también ha bajado (de 11,78 a 11,41)».

Desde un punto de vista lingüístico, son reseñables las construcciones de las dos primeras oraciones, pues en ellas no hay expresión alguna del agente. Las interrupciones «se practicaron» en ambos casos, pero se evita deliberada o involuntariamente decir quién las practicó. Esto, junto a la utilización del eufemismo, nos sitúa en un marco de despersonalización; acerca el tratamiento discursivo del aborto a la impersonalidad y promueve el distanciamiento del lector con respecto a esa realidad. Sin embargo, en la tercera de las frases aparece ya la expresión de un sujeto-agente, «el ministerio»: es el ministerio, también, quien sustenta y hace uso del eufemismo, del mismo modo que el autor de la noticia. En el análisis de los participantes, por tanto, deberemos tener en cuenta, también, al ministerio, pues la noticia es, en parte, una reproducción de sus palabras y de las de la ministra, y forman parte del esquema enunciador/enunciatario (terminología a la que recurren Calsamiglia y Tusón (2007)). Además de la utilización del eufemismo y la impersonalidad —esta última en los dos primeros casos- se introduce un matiz positivo al informar de que los abortos bajaron en 2009 por primera vez en diez años. Matiz positivo que se ve reforzado por la inclusión en la noticia de un enlace a otra noticia cuyo titular es: «El aborto no deja de ser un fracaso de información sexual». No se entiende, por tanto, por qué se intenta suavizar una realidad para que parezca menos incómoda de lo que resulta y, a la vez, se sugiera, veladamente, que es negativa: por ello se presenta como positivo que los abortos hayan bajado.

$\mathrm{Si}$ atendemos al contexto, haremos referencia a los siguientes elementos que Brown y Yule (cit. por Calsamiglia y Tuson, 2007: 103) recogen como pertenecientes al contexto y necesarios para un correcto análisis de una pieza discursiva: tema, marco, canal, código y características de los participantes. En primer lugar, el tema es el del aborto, comúnmente polémico y socialmente uno de los que más debate genera. En cuanto al canal, se trata de la edición en línea de un periódico de tirada nacional, y el código, como en el resto de noticias que aquí reproduzcamos, será el español. Por lo que respecta al marco, el espacio-temporal se sitúa en la España de 2010, aunque la noticia hace referencia al año 2009. En lo socio-cultural nos encontramos ante un marco en el que el aborto ha sido ilegal en España hasta 1985 
— legalizado solo en algunos supuestos-y cuya segunda ley se aprobó en 2010. Culturalmente, por tanto, el aborto ha sido en la sociedad española, hasta no hace tanto, una acción reprobable y fuera de los límites de la legalidad. Dicha sociedad se muestra aún hoy dividida entre aquellos que están en contra del aborto y los que se muestran a favor - aunque una afirmación de este tipo, en otro tipo de estudios especializados, pueda resultar sumamente simplista-.

Por último, sobre los participantes, debemos decir que uno de ellos es Emilio de Benito, emisor de la noticia y con capacidad, gracias al medio de comunicación en el que escribe, de llegar a miles de receptores. El autor incluye, a su vez, como emisores participantes, al ministerio y la ministra, pues reproduce sus palabras. Por tanto, parece que su papel es simplemente ese, el de reproductor de una información y un eufemismo que le vienen dados. No olvidemos, no obstante, la afirmación de Gallud (2005) que ya recogíamos anteriormente: son los comunicadores quienes tienen la oportunidad, desde sus medios, de desechar términos eufemísticos bajo los que se pretende la manipulación. No desecharlos se convierte en un hecho reprobable. En esta noticia, por tanto, el autor, que en primer lugar tendría un papel de mero informador, pasa a convertirse, mediante la perpetuación del eufemismo, en un manipulador del lenguaje y de los receptores que lo leen. Así, tanto el autor como el ministerio y la ministra, en primera instancia, para no hacer un uso malintencionado del lenguaje que pueda llevar a confusión a los receptores o a suavizar una realidad tan polémica como la presente - han de ser ellos quienes decidan si la suavizan o no-, deberían referirse como aborto al fenómeno al que ahora se refieren como interrupción voluntaria del embarazo. Se evitaría así la trasgresión de la máxima de modo o manera propuesta por Grice, pues la expresión no sería oscura. Por lo que se refiere al receptor y al proceso de decodificación del mensaje, no podemos dejar de nombrar el concepto de frame (así como los de guion y plan), términos del ámbito cognitivo utilizados para designar la organización que se produce en la mente de los hablantes de los datos que han ido recogiendo de la experiencia (Calsamiglia y Tusón, 2007: 110). Con esquema (o el más conocido frame) se hace referencia al conocimiento de los parámetros prototípicos de una determinada situación. Cuando ese frame se activa tienen lugar las expectativas de actividades que se deben llevar a cabo - guion-; estas indican cómo actuar y cómo es esperable que actúen los demás. Si consideramos, además, que la comunicación tiene una finalidad, se pondrá en marcha un determinado plan que servirá para conseguir dicha finalidad u objetivo. Así las cosas, desde el punto de vista del receptor, en este caso concreto, al activarse el frame, el lector se encuentra frente a una pantalla que reproduce una noticia de la edición en línea de un diario. Dicha información, dicho frame, le permite prever una serie de secuencias habituales de acontecimientos (Calsamiglia y Tusón, 
2007: 110): leerá la noticia, esperará quedar informado y que la noticia sea veraz. Sin embargo, se produce una pequeña ruptura de expectativas de la que el lector, incluso, puede no ser consciente: la noticia es veraz, el número de abortos descendió en 2009, sin embargo, la información se ve oscurecida parcialmente por la utilización del eufemismo «interrupción voluntaria del embarazo» (eufemismo que algunos periodistas han tildado, incluso, de $«$ cínico $»^{4}$. Suavizar esta realidad queda del lado del ministerio, ministra y periodista, cuando la decisión final debería ser del propio lector. Es de este modo como se opera una triple manipulación, no solo del receptor, sino de la realidad, del referente y del receptor.

\subsection{Obstáculos laborales}

Este eufemismo, sustituto de huelga, ha experimentado un auge en los últimos tiempos, según se puede constatar en la prensa tanto nacional como local. Es el caso de la siguiente noticia perteneciente al diario $A B C$ (en su edición en línea gallega $)^{5}$ : «Xunta y sindicatos desbloquean nuevos obstáculos laborales». Desde el punto de vista lingüístico nos hallamos ante una manipulación flagrante del referente: la perífrasis utilizada convierte al término interdicto huelga en un simple eufémico obstáculo laboral, expresión que no da cuenta de la realidad a la que realmente se está haciendo referencia. Más adelante, encontraremos un nuevo eufemismo de huelga: crisis. « La comparecencia que hoy llevará a Ethel Vázquez a la tribuna de O Hórreo ofrecerá a la oposición la oportunidad de recriminar directamente a la Consellería su gestión al frente de la crisis».

Además, no hallamos referencia alguna a la labor de los trabajadores que secundan la huelga: el transporte. Así, en la primera referencia a los trabajadores que convocaron la huelga, tendríamos un escueto «el acercamiento experimentado entre la administración y los trabajadores se cocinó en un encuentro de más de cinco horas de duración». Cabe que el lector se pregunte, en este punto, a qué sector pertenecen los trabajadores, al menos. Si avanzamos en la noticia encontramos un «al final, la fumata blanca se tradujo en un pacto, otro, que atiende a las reivindicaciones sobre las condiciones salariales y laborales del personal». ¿De qué personal?, se podría alguien preguntar, además de quedar un tanto extrañado por la reiteración de la idea

${ }^{4}$ La solución final. (30 de abril, 2017). El Mundo. Recuperado de: http://www.elmundo.es/ opinion/2017/04/30/5904c23a46163ff9748b46b8.html

5 Nespereira, N. (11 de julio, 2017). Xunta y sindicatos desbloquean nuevos obstáculos laborales. $A B C$. Recuperado de: http://www.abc.es/espana/galicia/abci-xunta-y-sindicatos-desbloquean-nuevos-obstaculos-laborales-201707111002_noticia.html 
de pacto mediante otro. La omisión de adjetivos o complementos que especifiquen puede suponer aquí una nueva manipulación: pareciera que no se quiere hacer hincapié en la figura de los trabajadores convocantes ni en su ámbito laboral. Ni siquiera más adelante, al hacer referencia a la rentabilidad de las «líneas» [de transporte] se especifica que son de transporte, omitiendo de nuevo un complemento necesario para la claridad de la noticia.

En cuanto a la información contextual, el tema es la negociación entre Xunta y sindicatos para mejorar las condiciones del personal de transportes. En el titular, sin embargo, y prácticamente en el resto del cuerpo de la noticia (solo aparece la palabra huelga en una ocasión), se evita hacer referencia a la huelga por la que se producen esas negociaciones, dejándolo en un simple obstáculos laborales o crisis. Tampoco es fácil dilucidar, como ya hemos señalado, de qué sector proviene la huelga y por qué se realiza, pues la palabra transporte solo aparece en una ocasión en el cuerpo de la noticia (línea 3), y referida al «plan de transportes». Con respecto al canal y al código, vuelven a ser los mismos que en la anterior noticia: la edición en línea de un periódico de tirada nacional y el idioma español, por lo que evitaremos repetirlos en el resto de ejemplos del corpus. En cuanto al marco espacio-temporal, es en esta ocasión local - Galicia-y de julio de 2017. En lo socio-cultural deberíamos profundizar en el concepto de huelga y en lo que suponen, a nivel local, la Xunta, los sindicatos y la patronal, un tema complejo en el que no se profundizará pero que puede situar tanto al autor como al receptor en diferentes sectores de la sociedad.

Refiriéndonos ahora a los participantes, el emisor es Mario Nespereira, periodista cuyo papel principal es el de informar, aunque en esta ocasión se desvíe del objetivo primordial. No solo por la utilización del eufemismo (incumplimiento de la máxima de manera de Grice, al ser oscuro en la expresión de huelga), sino por el hecho de incumplir la de cantidad: no da tanta información como es precisa para que la noticia sea totalmente clara y no cree confusión en el receptor, que puede preguntarse, de no ser por el soporte gráfico (la foto de la estación de autobuses), de qué huelga se está hablando ni si se está hablando de negociaciones fruto de una huelga. Esa falta de claridad es precisamente la que puede suponer, en el receptor, la ruptura de expectativas generadas por el frame. El lector espera, en un marco de esas características, terminar de leer la noticia estando informado y, sin embargo, en este caso concreto, puede terminar su lectura sin saber de qué sector es la huelga y sin saber, asimismo, que dicha huelga ha desencadenado las negociaciones entre Xunta

${ }^{6}$ Verdú, D. (14 de abril, 2016). Sobrevivir al matadero. El País. Recuperado de: https://elpais. com/ccaa/2016/04/13/catalunya/1460547371_634790.html 
y sindicatos.

Otro ejemplo claro de manipulación mediante este eufemismo lo encontramos en una noticia de El País sobre la huelga de los trabajadores del matadero de Vic (Cataluña) ${ }^{6}$ : «El conflicto laboral de un matadero de Vic destapa la dureza y las condiciones de trabajo de los inmigrantes de la industria porcina, con casos de explotación investigados y racismo». De que ese denominado conflicto laboral se trata en realidad de una huelga no es consciente el lector hasta bien entrado el cuerpo de la noticia, al encontrarse con «Lo mismo piensan otros 20 compañeros entrevistados por EL PAÍS después de que hace dos semanas, por primera vez, se revolviesen contra los empresarios del sector cárnico catalán con dos días de huelga», única vez junto a «Julio Risque, otro trabajador que participó en la huelga, asegura que Ramisa también amenazó con pegarles "cuatro tiros" » que aparece la palabra huelga en una noticia de diez extensos párrafos. Encontramos aquí cómo, de nuevo, mediante un eufemismo, se intenta manipular la realidad, al referente - pues no es un conflicto, es una huelga - y al receptor, que cognitivamente tendrá que hacer un esfuerzo de procesamiento mayor al habitual para llegar a saber que a lo que la noticia se está refiriendo es a una huelga de los trabajadores del matadero de Vic. No queda claro, no obstante, el porqué de este rechazo a la palabra huelga en la noticia. Quizás se quiera, de algún modo, poner el foco de atención en las causas por las que surge el conflicto (racismo, malas condiciones laborales que pasan por asumir los costes del material con el que trabajan, mafias, etc.) y no incidir en el concepto de huelga, pues dadas las connotaciones que en muchas ocasiones se le otorga a esta palabra, los trabajadores podrían ver mermada su credibilidad. Sea como fuere, El País debería ser responsable de no perpetuar ni reproducir eufemismos, quizás surgidos en otros ámbitos — quizás no-, que puedan influir manipulativamente en el modo en que el lector entiende la noticia o configura su opinión sobre el tema tras leerla. La función, aquí, debería ser la meramente informativa desde un principio: un grupo de trabajadores del matadero de Vic convoca una huelga por las condiciones laborales de su puesto de trabajo. A partir de ahí, incidir en unos u otros aspectos tendría también su propia relevancia discursiva - todo discurso es una suma de elecciones - , pero la información básica se habría ofrecido clara e íntegra desde el comienzo, de modo que el lector sepa a qué atenerse.

\subsection{Asistente sexual:}

Uno de los terrenos más fértiles para el cultivo de los usos eufemísticos ha sido y sigue siendo el de la prostitución. Lejos de perder vigencia los sustitutos eufemísticos para la palabra prostituta, como ha sucedido en otros ámbitos, son cada vez más los que encontramos en la prensa. Uno de los que más llamó nuestra atención fue el 
aparecido en la edición en línea del diario $\mathrm{ElMundo}^{7}$ : «Marien, asistente sexual de minusválidos». Ya desde el titular encontramos el eufemismo más llamativo de entre los que aparecerán en el artículo. Si seguimos avanzando, encontramos la siguiente frase: «Las trabajadoras del sexo lo ven como 'un servicio social'». De nuevo un eufemismo, trabajadoras del sexo, para evitar prostitutas, vocablo con fuertes connotaciones en nuestra sociedad. Es en la línea seis cuando por vez primera aparece directamente el término prostituta. Sin embargo, lo hace acompañado de un matiz positivo, que suaviza la dureza que para algunos pueda contener el término: «Ella es prostituta. Pero con una especialidad que la hace distinta. Única. Marien atiende a discapacitados $\gg$. Mediante la introducción del contraargumentativo fuerte pero, se le atribuyen a Marien y a su trabajo como prostituta cualidades que normalmente no van asociadas a esta ocupación: especialidad, distinta, única y, especialmente, atiende. Es prostituta, sí, se viene a decir, pero ejerce una prostitución, pareciera, cargada de valores positivos. Ni rastro, aún, de alusiones sexuales. Encontramos, por tanto, cuando no es sustituida por el ya citado eufemismo, una palabra a la que habitualmente se le atribuyen connotaciones negativas — prostituta — rodeada de léxico positivo, suavizando así esas connotaciones. Más adelante encontramos la repetición del verbo atender, un nuevo eufemismo, para hacer referencia a mantener relaciones sexuales: «Ella encontró su senda atendiendo a aquellos que ninguna otra prostituta

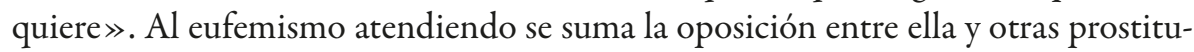
tas: ella propietaria de todas las virtudes positivas que se le han atribuido anteriormente frente a ninguna otra porque no atienden a discapacitados. En la primera pregunta que el periodista le realiza a la prostituta, ella contesta: «En los clasificados ponía desde un principio que atendía a discapacitados. Me especialicé ». De nuevo el verbo atender y de nuevo la nula alusión al terreno sexual. En ese mismo párrafo, un nuevo eufemismo para sustituir a prostituta: escort, en este caso un extranjerismo que en la lengua desde la que nos ha llegado, el inglés, también es un eufemismo de prostituta, pues su significado original es el de 'acompañante'. Seguimos avanzando en la crónica y encontramos la siguiente frase, referida ya a uno de los encuentros sexuales concretos entre Marien y un cliente: «Su último servicio antes del encuentro con Crónica, un hombre [llamémosle Juan] con esclerosis lateral amiotrófica, la terrible ELA». Último servicio podríamos catalogarlo, también, como eufemismo del gran ausente a lo largo del texto: encuentro sexual. Una única alusión a dicha realidad, aunque no directa, encontramos en ese mismo párrafo, cuando el periodista escribe: «Marien, profesional, hizo su trabajo. Le dio placer». Hacia el final

${ }^{7}$ Mucha, M. (19 de abril, 2009). Marien, asistente sexual de minusválidos. El Mundo. Recuperado de: http://www.elmundo.es/elmundo/2009/04/18/espana/1240089766.html 
de la crónica hallamos, de nuevo, el eufemismo del titular con el que se comienza: «En los cantones suizos de habla alemana los asistentes sexuales ejercen libremente desde hace seis años». Lingüísticamente, por tanto, además de los eufemismos, observamos en esta noticia toda una serie de léxico con connotaciones positivas que rodean a la figura de Marien. Aparece también la oposición que ya señalaría Van Dijk (2009) en otros contextos entre ella — asociada a características positivas- y otras - asociadas a características negativas por no atender a discapacitados-.

Si atendemos al contexto, debemos hablar en primer lugar del tema, al que ya hemos hecho referencia anteriormente: la prostitución, de carácter polémico aún hoy día en nuestra sociedad. Prueba de esta polémica es que en el marco espacio-temporal de la España de 2009 (en ese año se escribió la crónica) aún se seguía recurriendo a eufemismos de todo tipo para nombrar esta realidad. Este hecho está profundamente unido al contexto social y cultural de España, donde habitualmente la prostitución y las prostitutas han sido un tema tabú, y se trata de una ocupación ilegal. Por ambas razones, quizás más por la primera, el de la prostitución es un ámbito donde, como hemos observado en la crónica, los eufemismos —en plural—están a la orden del día y son abundantes.

Por último, resta destacar el papel del receptor en este contexto. Puede presuponerse, por el marco socio-cultural antes citado, que el lector se enfrente al texto activando un frame en el que la prostitución debe ser tratada y mencionada de manera suavizada, atenuada. Lo contrario, quizás, rompería sus expectativas: hablar directamente de prostitución, prostituta, burdel o sexo podría resultar violento; sin embargo, aducir una razón así para utilizar eufemismos del tipo asistente sexual no parece lo más profesional. No hacer ninguna referencia al sexo, tampoco. Esto, evidentemente, no generaría dudas en el receptor sobre la ocupación de la asistente sexual, sin embargo, oscurece el mensaje innecesariamente y puede llevar al lector -mediante la manipulación - a un lugar, a una concepción u opinión concreta de la prostitución, o del caso específico, que no le tendría por qué venir dada (menos aun en una crónica).

\section{Eufemismos sobre violencia}

Numerosísimos son los eufemismos referidos a la violencia que, a lo largo de la creación de este corpus, hemos encontrado. Por ello, fruto de su abundancia, se ha hecho necesaria la inclusión de un apartado temático que recoja expresiones eufemísticas referidas a las guerras, los terroristas o las víctimas.

\subsection{Grupo violento/Grupo separatista}


Ambas denominaciones, la de grupo violento y la de grupo separatista, se han encontrado en la prensa escrita haciendo referencia al grupo terrorista ETA. La primera de ellas la encontramos en la $\mathrm{BBC}^{8}$, sección internacional: «El grupo separatista vasco ETA entrega su arsenal de armas a las autoridades en Francia ». La bajada del titular sigue conteniendo el eufemismo: «El grupo separatista vasco ETA inició el proceso de entrega de todo su arsenal de armas, formalmente poniendo fin al último movimiento insurgente en Europa ». En uno de los siguientes párrafos, se le denomina únicamente como grupo, sin la utilización de violento: «En 2011, el grupo declaró un cese el fuego pero no se desarmó. No obstante, Francia y España se rehusaron a negociar con ETA», y más adelante el eufemismo grupo violento pasa a ser grupo radical: «El viernes, el grupo radical se declaró "una organización desarmada” $\gg$. Llama la atención también, en la propia noticia, un enlace a una nueva noticia cuyo titular es «Los separatistas vascos de ETA se declaran "una organización desarmada" ».

Desde un punto de vista lingüístico el eufemismo queda claramente reflejado en la utilización de los adjetivos violento, separatista y radical, ninguno de ellos equivalente a terrorista y, por tanto, atenuantes del terror que ETA se ha encargado de infundir en España. Una vez más, encontramos manipulación no solo del referente, sino de la realidad referida, pues ETA no era una banda únicamente violenta, separatista o radical - aunque fuera, por supuesto, estas tres cosas-, sino, y sobre todo, terrorista. Se produce por tanto una violación de la máxima de cantidad, pues la $\mathrm{BBC}$ no proporciona toda la información que se precisa para entender la naturaleza de ETA, que no es otra que la de banda terrorista. Esta manipulación de la realidad referida puede dar lugar, sin duda, a la manipulación del receptor de la noticia. Si se trata de alguien que no sabe que ETA era una banda terrorista, continuará sin saberlo tras leer la noticia, pues no se especifica. No se trata aquí ya, por tanto, de un simple oscurecimiento de la expresión, sino de una omisión de información relevante para que el receptor interprete correctamente la noticia.

Debemos atender, asimismo, al contexto. El tema de la noticia es el desarme de ETA, en unas coordenadas espacio-temporales cercanas, pues se produjo en abril de 2017 y en Bayona, territorio francés muy cercano a España. El marco socio-cultural sobre el que se asienta esta realidad es ya bien conocido por todos debido a su cercanía temporal y espacial y al impacto que siempre ha provocado en la sociedad española. ETA comenzó a asesinar en el año 1968 y declaró el cese de la actividad

${ }^{8}$ El grupo separatista vasco ETA entrega su arsenal de armas a las autoridades en Francia. (8 de abril, 2017). BBC. Recuperado de: http://www.bbc.com/mundo/noticias-internacional-39538669 
armada en 2011; durante ese período infundió el terror entre la sociedad civil y los diferentes órganos del estado. El grupo terrorista, por tanto, sigue siendo entre la sociedad del país una realidad cercana y cuyo tratamiento es sensible.

Por lo que respecta a los participantes, desconocemos el autor de la noticia, pues aparece firmada por la redacción del medio. Acerca del autor cabe hacerse la siguiente pregunta: ¿califica a la banda terrorista ETA como separatista o violenta por desconocimiento, por no considerarla actualmente terrorista al estar ya desarmada o por alguna intención manipulativa? Sea cual fuere la respuesta, y aunque la intención última no fuese la de manipular la realidad, el referente o al receptor, es lo que se consigue, al menos en aquellos receptores internacionales que desconocen la existencia de ETA y que, tras su conocimiento, no la tendrán como una banda terrorista porque la noticia no los ha informado de ello; o bien en aquellos que, conociendo a ETA, tras la lectura de la noticia tengan una imagen menos negativa de la banda, motivada precisamente por esos adjetivos eufemísticos. En este sentido, podríamos señalar dos tipos de receptores con frames diferentes: uno, nacional, que espera que se califique a ETA de banda terrorista y que tras no encontrar dicha denominación vea rotas sus expectativas (o bien, como hemos dicho, pase a tener una imagen menos negativa de ETA); otro, internacional, que sin contar con información sobre el contexto socio-cultural español es mal informado y cognitivamente, debido a la manipulación de la realidad, es también él manipulado, no considerando a ETA como lo que realmente es: una banda terrorista.

\subsection{Daños colaterales}

Generalmente, se utiliza el eufemismo daños colaterales para sustituir a muertes o incluso asesinatos. Daños colaterales es una expresión aséptica que provoca una profunda despersonalización: se resta importancia a cuáles sean esos daños, generalmente en vidas humanas, y se puede generalizar sin recurrir al incómodo campo semántico de la muerte. Así lo encontramos en la noticia que publica el diario El Mundo': «Los 'daños colaterales' de la batalla de Mosul». Más adelante volvemos a encontrar el eufemismo: «Desde entonces los medios de comunicación afines al grupo yihadista han tratado de explotar los "daños colaterales" de la alianza difundiendo los crudos fotogramas de las víctimas». No obstante, vemos aquí como en las dos ocasiones daños colaterales está entrecomillado. Se trata de un recurso

${ }_{9}^{9}$ Carrión, F. (18 de noviembre, 2016). Los 'daños colaterales' de la batalla de Mosul. El Mundo. Recuperado de: http://www.elmundo.es/internacional/2016/11/18/582dfc98e2704e2b758b4616. html 
de ciertos medios escritos, que incluso aparece en sus libros de estilo, para señalar los eufemismos. Dichas comillas, no obstante, pueden decirle poco al lector, y a lo largo de la noticia no se establece la identidad entre daños colaterales y asesinatos o muertes, por lo que la información queda oscurecida debido a un proceso eufemístico. En el momento en que el coste de procesamiento para el receptor es mayor de lo habitual a la hora de interpretar los enunciados, debemos estar alertas y preguntarnos por qué: ępor qué no se realiza una fácil identificación —como las que los receptores hacen habitualmente, casi de manera automática - entre daños colaterales y el cobrarse la vida del siguiente enunciado? Dicho enunciado es el que sigue: «Los ataques aéreos se cobran la vida de 180 civiles cuando se cumple un mes del inicio de la ofensiva sobre el bastión iraquí del Estado Islámico». Resulta evidente que esos daños colaterales son las 180 muertes de los civiles; ahora bien, debemos hacer un esfuerzo mayor de procesamiento - aunque sea mínimamente mayorpara interpretar que daños colaterales se está refiriendo a esas 180 muertes, pues no existe ningún mecanismo lingüístico que conecte las dos realidades (dos realidades que son una y la misma).

Refiriéndonos ahora al contexto, debemos determinar que el tema de la noticia son las víctimas de la batalla de Mosul. Y encontramos ya aquí el primer problema del eufemismo daños colaterales, pues no permite identificar claramente el tema desde el titular de la noticia. Se trata, por tanto, de un oscurecimiento del sentido y de una manipulación del referente (en este caso los referentes) que puede dar lugar a una mala interpretación de la noticia por parte del receptor al leer el titular. En cuanto al marco espacio-temporal, esos daños colaterales se producen en el años 2016 en Mosul, territorio fuertemente hostigado por los enfrentamientos. De la mencionada ciudad en dicha fecha se puede establecer ya un marco socio-cultural claro: zona de guerra, de enfrentamientos, donde se producen muertes habitualmente. El desconocimiento de un país tal impide la profundización en este tipo de marco, pero para la labor que nos atañe, basta con saber que la situación social actual es desfavorable para los civiles, con ataques continuos a la población.

Por último, sobre los participantes, debemos decir que aunque el autor de la noticia entrecomille daños colaterales, no deja de usar el eufemismo y de contribuir a una oscuridad significativa que puede llevar a la mala interpretación del titular de su noticia. Por tanto, quizás, tal como señalábamos más arriba y como sostenía Gallud (2005), debiera sustituir el término eufemístico por uno que diera realmente cuenta de la realidad referida y no se prestara a una manipulación del referente.

\subsection{Bajas}

Bajas es el sustituto eufemístico que ocupa el lugar, en ocasiones, de muer- 
tes. Así lo vemos en el titular de la siguiente noticia en línea del periódico $A B C^{10}$ : «El aumento de las bajas acelera los contactos para un alto el fuego en Gaza $»$. El eufemismo aquí es completamente léxico: una palabra se sustituye por otra, sin mediar ningún procedimiento más que el de la sustitución. Encontramos de nuevo, más adelante, el mismo eufemismo: «La lista de bajas no deja de crecer en esta operación $[\ldots] \gg$. Si en el primer caso el término bajas evoca ya cierta despersonalización, pues no se hace referencia a víctimas o personas, ni tampoco a la causa o agente que ha provocado tales bajas, en el segundo caso la impersonalidad es tal que ya ni siquiera son bajas, sino una lista de bajas. Por tanto, dicha despersonalización es la que provoca, en parte (junto al uso, por ejemplo, del muy genérico los contactos), que el titular sea uno de los menos claros de los que en este corpus hemos reproducido: ¿de qué bajas (víctimas) se está hablando?, ¿qué contactos se aceleran?, ¿por parte de quién se producen tanto las víctimas como los contactos?

Si prestamos atención al contexto de la noticia, tras leer el titular nos será incluso difícil establecer el tema, pues la utilización del eufemismo bajas junto a la generalización de aumento y contactos convierte la información en un entramado de expresiones difíciles de interpretar. Al leer la noticia, accedemos, por fin, al tema: el aumento de muertes tanto palestinas como israelíes y de población civil y soldados provoca que se inicien conversaciones entre el representante de EEUU y las autoridades de El Cairo para poner solución a tan crítica situación. Por lo que respecta al marco espacio-temporal, las muertes sobre las que pretende informar la noticia suceden en la franja de Gaza en el año 2014. Ese marco espacio-temporal acarrea unas fuertes implicaciones tanto sociales como políticas, religiosas, etc. Un marco socio-cultural, en definitiva, excesivamente complejo y que se encuentra entre dos religiones, culturas y formas de entender el mundo. Esa excesiva complejidad se ve agravada en noticias como la aquí analizada: si de un conflicto de estas dimensiones y complejidad no se informa debidamente, la confusión en el receptor puede ser aún mayor. Apelamos, de nuevo, a la responsabilidad social de la figura del periodista: no es culpable por reproducir eufemismos que ya vienen dados, pero sí lo convierte en cómplice el hecho de crear su propia información valiéndose de dichos eufemismos o expresiones vagas u oscuras. Ese hecho, en este caso, manipula la realidad: no se trata de bajas, sino de muertes de víctimas de un conflicto. Se cae en la posible manipulación, además, del receptor, pues cuando termine de leer el titular de la presente

${ }^{10}$ Ayestaran, M. (21 de julio, 2014). El aumento de las bajas acelera los contactos para un alto el fuego en Gaza. $A B C$. Recuperado de: http://www.abc.es/internacional/20140721/abci-israel-margen-protector-kerry-201407212018.html 
noticia puede quedar manipulado cognitivamente al apreciar como atenuada una realidad que no es otra que la muerte.

\section{Eufemismos económicos}

\subsection{Rescate}

Los eufemismos económicos son numerosos, pues en un terreno tan delicado como es el de la economía se necesita, en muchas ocasiones, atenuar la realidad y reelaborar la denominación de realidades que pueden afectar de manera directa al dinero de los contribuyentes. Es este el caso de adelanto para obtener liquidez, que generalmente es sustituido por rescate. Así lo podemos ver, expresado mediante el eufemismo rescate, en la siguiente noticia del $A B C^{I I}:$ :El Gobierno defiende que el rescate a los bancos evitó la pérdida de 112.000 millones de depósitos»; seguidamente, en la bajada del titular, «De Guindos ha asegurado que la alternativa hubiera sido "mucho peor" y que el FROB ha recuperado ya 7.000 millones». Lingüísticamente, el titular comienza con el sujeto que defiende, en este caso el Gobierno, en lo que podríamos considerar un argumento de autoridad: si la mayor autoridad del Estado así lo considera (y no solo lo considera, sino que lo defiende), el rescate debe de ser positivo, más aun cuando evitó la pérdida de miles de millones. Dos verbos semánticamente fuertes (evitó y defendió), la alusión a una gran suma de dinero y el argumento de autoridad se convierten en mecanismos que refuerzan el eufemismo, es decir, que refuerzan lo positivo del rescate para el país. En el siguiente enunciado encontramos una estructura similar al comienzo del titular: en esta ocasión el argumento de autoridad es De Guindos y hallamos también un verbo semánticamente fuerte: asegurar. El ministro no solamente ha dicho o ha sostenido, sino que ha asegurado. La alusión a la alternativa supone una variante de la oposición que señaló Van Dijk entre ellos y nosotros. En este caso, entre la opción elegida por el gobierno y la alternativa. Se intenta hacer una caracterización positiva de la primera y una negativa de la segunda, como podemos observar en ambos enunciados: el rescate evitó la pérdida, mientras que la alternativa habría sido mucho peor. Connotaciones positivas enlazadas al eufemismo, connotaciones negativas en torno a la alternativa. Como decimos, estos mecanismos no hacen más que reforzar la función que tiene aquí el eufemismo rescate: la de no nombrar directamente que se trata de un adelanto de dinero para poder obtener liquidez. Además, casi al final de la noticia,

${ }^{11}$ EFE (17 de junio, 2017). El Gobierno defiende que el rescate a los bancos evitó la pérdida de 112.000 millones de depósitos. $A B C$. Recuperado de: http://www.abc.es/economia/abci-gobierno-defiende-rescate-bancos-evito-perdida-112000-millones-depositos-201706271953_noticia.html 
encontramos otro término con resonancias eufemísticas, al referirse al hecho del adelanto para obtener liquidez como saneamiento: «De Guindos ha defendido que este "saneamiento" del sector ha llevado al actual crecimiento económico por encima del $3 \%$ del PIB».

Contextualmente, debemos atender en primer lugar al tema de la noticia, que no es otro que la defensa del rescate por parte del gobierno; pues no se aportan datos sobre el hecho en sí, sino sobre la defensa que el gobierno - especialmente De Guindos- hace del rescate. Tanto es así que en la primera línea de todos los párrafos que tiene la noticia (7) aparece nombrado De Guindos: «el ministro de Economía, Luís De Guindos», «De Guindos ha asegurado», «el ministro de Economía ha explicado», «De Guindos ha comentado», «el ministro ha puntualizado», «(el ministro) ha citado»y, para terminar, «De Guindos ha defendido». Dicha estructura (que sitúa como protagonista de la noticia al ministro por encima de la información sobre el rescate y, además, rodea al eufemismo rescate de toda una serie de términos positivos) da cuenta de cuál es la temática de la noticia y cuál es aquí la intención: la de reproducir ese acuerdo con respecto a lo positivo del rescate. En cuanto al marco espacio-temporal, la noticia se sitúa en la España del 2017, pero haciendo referencia a un hecho que se produjo en 2012. Se analizan, por tanto, las consecuencias del adelanto monetario que se produjo en aquel momento. Para el gobierno, como se ve, positivas; para el Banco de España no tan positivas, pues como se extrae de una noticia ${ }^{12}$ del mismo diario publicada once días antes: «El Banco de España estima que solo es recuperable una quinta parte de las ayudas a las cajas». No obstante, aunque no parece teñirse aquí el rescate de una connotación tan positiva, se sigue utilizando en el propio titular otro eufemismo para referirse al adelanto: ayudas. Por último, en cuanto al marco socio-cultural por el que se ve envuelta la noticia, nos situamos en un contexto de crisis económica y financiera en un país cuyos conocimientos generales sobre economía no son todo lo completos que deberían (quizás porque la formación económica se presenta casi como optativa en el sistema educativo español). Sin embargo, por esos conocimientos económicos, tanto los políticos como los medios de comunicación deberían ser especialmente cuidadosos con la terminología a la que recurren para referirse al tema. Si, como en este caso, acuden a eufemismos que oscurecen las expresiones y las informaciones, puede tener lugar la manipulación del receptor, al hacerse este una idea equivocada de la realidad a la que se está aludiendo con el término rescate. Una vez más, por tanto, se presenta aquí

${ }^{12}$ Veloso, M. (16 de junio, 2017). El Banco de España estima que solo es recuperable una quinta parte de las ayudas a las cajas. $A B C$. Recuperado de: http://www.abc.es/economia/abci-banco-espana-estima-solo-recuperable-quinta-parte-ayudas-cajas-201706161233_noticia.html 
la figura del periodista como cómplice de la utilización de eufemismos que tienen como intención manipular o, si no la tienen, pueden llegar a hacerlo. Un periodista que reproduce la terminología a la que recurre el gobierno y no intenta sustituirla en su información por el término adecuado que aportaría claridad a la noticia.

Sobre la utilización de este eufemismo, no obstante, resulta curioso que, aunque lo sea, fuera evitado por los portavoces del gobierno de la época. El ministro De Guindos, el único que compareció el mismo día en que se hizo efectivo el rescate, evitó el eufemismo, refiriéndose a la situación como «crédito europeo en situaciones muy favorables ${ }^{13}$. Mariano Rajoy, un día después, en su rueda de prensa sobre la situación, utilizó la expresión «línea de crédito europea». Se pretendía, así, no evitar el eufemismo rescate, sino no hacer alusión a una realidad que la sociedad española tenía muy presente y que se había generalizado mediante la denominación rescate.

\subsection{Gravamen a activos ocultos}

Gravamen a activos ocultos es el eufemismo que el ministro Montoro utilizó para referirse a la amnistía fiscal que tuvo lugar en España en 2012. Así lo vemos en la siguiente noticia de Diario de Sevilla ${ }^{14}$ : «Montoro: "No es una amnistía fiscal, es un gravamen a activos ocultos" ». Sus declaraciones sobre «la regularización de cuentas ocultas» (un nuevo eufemismo), aparecen resumidas en el siguiente párrafo: «En cuanto a la regularización de rentas ocultas, el ministro ha hecho hincapié en que "no es una amnistía fiscal", sino "un gravamen sobre activos que están ocultos y cuyo afloramiento será positivo para normalizar la actividad económica en nuestro país" y luchar contra la economía sumergida. Las rentas no declaradas que afloren antes del 30 de noviembre pagarán un gravamen del $8 \%$ o del $10 \% \gg$. Es decir, no se trata de una regularización de dinero no declarado sin que medie en el proceso sanción fiscal alguna, sino que se pone el punto de atención en el gravamen (del $10 \%$ ) que los que se acojan a la amnistía fiscal tendrán que pagar. Visto desde esta perspectiva, solo se pone de manifiesto la parte positiva de la actuación: el tributo que se deberá pagar por declarar dinero ilegal. Un dinero ilegal al que se llama acti-

${ }^{13}$ Del Ser, G. (9 de junio, 2017). El año en que nos rescataron (pero ganamos la Eurocopa). El País. Recuperado de: https://economia.elpais.com/economia/2017/06/08/actualidad/1496942880_041914.html

${ }^{14}$ EFE. (12 de abril, 2012). Montoro: "No es una amnistía fiscal, es un gravamen a activos ocultos". Diario de Sevilla. Recuperado de: http://www.diariodesevilla.es/economia/Montoro-amnistia-gravamen-activos-ocultos_0_578342663.html 
vos ocultos, ni siquiera escondidos a conciencia por aquellos que deciden delinquir, sino ocultos. Estos eufemismos, además, se ven reforzados por un contexto positivo como el que ya señalábamos en anteriores ejemplos del corpus. El afloramiento de esos activos ocultos será «positivo» e incluso ayudará a normalizar la actividad económica del país. ¿Quién podría estar en contra de una medida de esas características vista desde esta perspectiva, donde todo son ventajas? Aquellos que oculten dinero ilegal no solo tendrán que pagar, sino que además ayudarán a la mejora de la situación económica del país. Es decir, el ministro Montoro, desde esta postura, toma una de las partes de las que se compondrá la amnistía fiscal (el pago de un gravamen) y considera esa parte como la más relevante (o incluso como la única relevante), situándola en primer lugar en su afirmación. De este modo convierte gravamen en un eufemismo para eliminar amnistía fiscal. Como hemos dicho, además, rodea al eufemismo de palabras cargadas de un contenido semántico positivo: afloramiento, positivo o normalizar.

Así las cosas, y según el contexto, el tema de la noticia no parece ser únicamente la amnistía fiscal, sino la explicación de por qué no se trata de una amnistía sino de un gravamen sobre activos ocultos. Por lo que respecta al marco espacio-temporal se trata de España en 2012, un momento de crisis económica y financiera, incluso de desesperación para muchos españoles. Dicho marco debemos tenerlo en cuenta al hablar también del socio-cultural. Como hemos apuntado, los conocimientos sobre economía de la población española pueden provocar que los ciudadanos se vean más expuestos a posibles manipulaciones cuando se habla en estos términos. Eso, sumado a la mala situación económica de España en 2012, puede causar estragos en los lectores que lleguen hasta estas informaciones, teniendo lugar la manipulación. Bien porque no entiendan la noticia ya que su oscurecimiento es extremo debido al uso de los eufemismos, bien porque extraigan de su lectura conclusiones que, de haberse informado debidamente al lector y de manera clara, no habrían extraído.

Por último, en cuanto al papel de los participantes, debemos destacar, una vez más, la actuación del periodista que escribe la noticia. Si bien es cierto que reproduce casi literalmente las palabras de Montoro, también lo es que él mismo utiliza un par de eufemismos para referirse a la amnistía fiscal: «regularización de rentas ocultas» y «economía sumergida». El término regularización otorga un matiz positivo a esas rentas, una vez más, ocultas, no escondidas por alguien concreto en algún lugar, hecho ilegal. Se omite continuamente, también en el caso de la noticia, el agente que oculta dichas rentas, el infractor fiscal. Parece, sin embargo, como hemos apuntado anteriormente, que, de aparecer referencia a ellos en algún momento, fueran una figura positiva para la sociedad española y su economía por el gravamen al que se van a ver sometidos. Economía sumergida, por último, hace referencia a esa 
economía que se trata de regularizar: la ilegal, la del dinero no declarado. Por tanto, y aunque sea normal que el periodista tenga que reproducir las palabras del ministro Montoro, no solo las reproduce, sino que sustenta los eufemismos manipuladores mediante más eufemismos con la misma función.

\section{Eufemismos políticos}

\subsection{Anexión}

En algunos casos el término anexión ha aparecido como sustituto eufemístico de invasión, y así lo trasladaremos, en esta ocasión, mediante la comparación de dos textos periodísticos, ambos del diario El Pais ${ }^{15}$ : una noticia y un reportaje. En el primero de ellos, el que titula la noticia como «Putin firma la anexión de Crimea a Rusia», solo aparece una vez el término invasión, y lo hace en una cita literal de Putin: «Pero, según su punto de vista, no se trata de una anexión ni de una invasión — “¿dónde ha habido una invasión sin enfrentamientos ni víctimas?”, inquirió- - y recordó que no había hecho uso de la autorización parlamentaria de enviar al Ejército. Simplemente no era necesario, explicó, pues los soldados rusos ya estaban en la península "de acuerdo con un tratado internacional" ». Apreciamos, por tanto, cómo el termino invasión solo se reproduce para poner en duda o desmentir la realidad de dicha invasión. El segundo texto, en cambio, cuyo titular es «La creciente tensión entre Rusia y Occidente tiene un escenario bélico posible: los países bálticos. La invasión rusa de Crimea (Ucrania) en 2014 desató las alarmas. [...]», utiliza la palabra invasión hasta en siete ocasiones, comenzando por el titular. Más adelante aparece, además, acompañada de militar, aunque justo en la anterior oración se refiere a anexión: «Lo que más ansiedad les provoca hoy [a los estonios] es un recuerdo más reciente: la anexión rusa de Crimea, en el este de Ucrania, en 2014. La invasión militar ordenada por el Kremlin hizo sonar las alarmas aquí y en el resto de Europa [...]». Hallamos, asimismo, un nuevo eufemismo para invasión en el mismo párrafo: $\ll[\ldots]$ precipitando la decisión de la OTAN de enviar batallones a los países bálticos esta primavera como medida disuasoria en caso de que Putin intente aquí otra expansión forzosa del territorio ruso». Expansión forzosa, así, como sustituto eufemístico de invasión. Si seguimos avanzando, volvemos a encontrarnos con invasión: «Por eso todos suman al recuerdo reciente de la invasión de Crimea [...]». Para fi-

15 Fernández, R. (18 de marzo, 2014). Putin firma la anexión de Crimea a Rusia. El País. Recuperado de: https://internacional.elpais.com/internacional/2014/03/18/actualidad/1395125826_603105. html y Carlin, J. (4 de junio, 2017). Tambores de guerra en el Báltico. El País. Recuperado de: http:// elpaissemanal.elpais.com/documentos/tambores-de-guerra-en-el-baltico/ 
nalizar, las dos últimas veces que aparece la palabra invasión lo hace para referirse a la posibilidad de que Rusia la lleve a cabo en Letonia y/o Estonia: en primer lugar, en un pie de foto, al mostrar a unos soldados «Miembros de la unidad de ciberdefensa de los kaitseliit estonios, grupos de voluntarios paramilitares formados para repeler una eventual invasión rusa ». En segundo lugar, al tratar de encontrar una explicación al porqué de la denuncia rusa sobre la situación de letonios y estonios: «La propaganda estatal rusa no deja hoy de denunciar que los cientos de miles de estos rusos apátridas en Letonia y Estonia, como los que conocí en la ciudad fronteriza de Narva, viven bajo el yugo de la injusticia y la opresión. La única manera de entender por qué difunden este mensaje es que están abonando el terreno en caso de que un día necesiten justificar una invasión ».

Al leer comparativamente ambos textos, la confusión es evidente: ¿̇se trata de una invasión, tal como se afirma en el reportaje, aunque a veces también se hable en él de anexión o, por el contrario, no se produjo invasión alguna, como parece derivarse de la lectura de la primera noticia, que no refleja en ningún momento esa realidad invasiva? Sea como fuere, en ambos casos la manipulación está latente, porque en ninguno de los textos se da toda la información necesaria (que no es otra que el hecho de que puede tratarse, o no, de una invasión): en el primero de ellos por omisión, en el segundo por dar cabida a los dos términos sin aclarar el porqué de la utilización de ambos (al menos en una de las ocasiones, donde forma parte del texto del reportaje y no es una reproducción de palabras de otra persona).

Bien es cierto que, si atendemos al contexto, el tema de ambos textos es diferente: el de la noticia es la anexión de Crimea a Rusia, el del reportaje es la posible situación de los países bálticos como escenario de guerra. No obstante, en el segundo, aunque no referido directamente a dicha anexión, también se trata el tema (podríamos decir que es un subtema o tema secundario a través del que se establece una comparación), y debiera hacerse con la misma precaución que si hablara únicamente de ese conflicto. En cuanto al marco espacio-temporal, aunque el de los hechos narrados coincide, el de los textos periodísticos no, pues el primero es de 2014 y el segundo de 2017. Esta distancia temporal puede haber sido la causante de la diferencia en el tratamiento del tema, pues la perspectiva temporal de 2017 puede proporcionar el suficiente distanciamiento como para tratar con objetividad los temas. Si esta interpretación fuera correcta, no se entiende por qué, entonces, en el reportaje se hace alusión tanto a invasión como a anexión.

Con respecto al papel de los participantes, cabe destacar tanto el del emisor como el del receptor, pues ambos juegan un importante papel. El emisor de la primera noticia lo juega porque decide ignorar la palabra invasión y solo hace alusión a la posibilidad de que lo sea cuando cita a Putin negando dicha posibilidad. Mani- 
pulación, por tanto, manifiesta, pues queda demostrado que conoce la posibilidad de que la anexión sea, en realidad, una invasión, pero no hace referencia a ello. Así, el lector de esta noticia podría quedar totalmente manipulado al pensar, por falta de información (o de incluir la otra posibilidad), que se trata, en efecto, de una anexión. El segundo emisor, del reportaje, se muestra totalmente ambiguo al utilizar ambas palabras e incluso algunos otros eufemismos, como ya hemos dicho, referidos a invasión. Ambiguo no por la utilización de ambas palabras para una misma realidad, sino por no dar cuenta de que existen dos posturas que él mismo refleja: la de que sea una anexión o la de que sea una invasión. Esta falta de especificidad puede llevar al lector a una confusión que desemboque en manipulación.

\subsection{Desaceleración}

El último de los eufemismos al que nos referimos en este corpus es el de desaceleración, un término que el gobierno español utilizó para referirse a los comienzos de la crisis que tuvo lugar en nuestro país en 2008. Así lo encontramos reflejado en noticias como la de Expansión.com ${ }^{16}$, cuyo titular apunta: «Zapatero continúa sin hablar de crisis económica aunque reconoce una “desaceleración” ». En el primer párrafo del cuerpo de la noticia, más que informar sobre la crisis, se hace referencia a la denominación de la misma por parte de Zapatero: «El presidente del Gobierno ha vuelto a insistir en que no ve que la economía española esté en un momento de crisis, aunque ha reconocido que atraviesa por "una desaceleración económica” ». No obstante, además de referencias al debate denominativo, encontramos periódicos que adoptan el eufemismo en sus noticias; tal es el caso del $A B C$, titulando así dos de sus textos: «Zapatero anuncia medidas «inmediatas» contra la desaceleración económica ${ }^{17} \gg ;$; «Zapatero reitera que España está preparada para afrontar la desaceleración económica ${ }^{18} \gg$. En la segunda de las noticias observamos cómo el propio diario hace suyo el eufemismo desaceleración económica para informar a sus lectores: «Zapatero ha rechazado asimismo tomar "medidas equivocadas"

16 Zapatero continúa sin hablar de crisis económica aunque reconoce una "desaceleración”. (28 de abril, 2008). Expansión. Recuperado de: http://www.expansion.com/2008/04/28/economia-politica/politica/1117403.html

${ }^{17}$ Zapatero anuncia medidas inmediatas contra la desaceleración económica. ( 8 de abril, 2008). $A B C$. Recuperado de: http://www.abc.es/hemeroteca/historico-08-04-2008/abc/Nacional/zapatero-anuncia-medidas-inmediatas-contra-la-desaceleracion-economica_1641778953960.html\#

${ }^{18}$ Zapatero reitera que España está preparada para afrontar la desaceleración económica. (28 de mayo, 2005). ABC. Recuperado de: http://www.abc.es/hemeroteca/historico-28-05-2008/abc/ Economia/zapatero-reitera-que-espa\%C3\%B1a-esta-preparada-para-afrontar-la-desaceleracion-economica_1641898602298.html\# 
en respuesta a la alusión de Rajoy al paquete de actuaciones económicas que los populares presentaron para hacer frente a la desaceleración y que el Gobierno optó, según el líder de la oposición, por “dejar de lado” ». Una vez más vemos cómo, en ocasiones, los periodistas, lejos de limitarse a reproducir las palabras eufemísticas que forman parte de lo noticiable, las adoptan como propias y contribuyen con ello a la manipulación tanto lingüística como de la realidad y del receptor. Al no aludir directamente, con palabras claras y precisas, a los hechos sobre los que informan, perpetúan usos eufemísticos utilizados como recursos manipuladores.

En el caso concreto de este eufemismo, el término se ha perpetuado en el tiempo, no ya para hacer referencia solo a la crisis, sino para denominar pequeños períodos temporales en que la economía es peor que la inmediatamente anterior. Lo encontramos en noticias más actuales (de 2015 y 2016) como estas de los periódicos El Pais ${ }^{19}$ («Desaceleración, pero moderada $)$ o El Mundo ${ }^{20}($ «l crecimiento de la economía española se desacelera en el tercer trimestre $)$.

Otra de las noticias que trata directamente el tema de este eufemismo la encontramos en el diario El Pais ${ }^{21}$ : «Zapatero asume ya la crisis». Al inicio de la misma, en el primer párrafo, encontramos el siguiente texto: «¿Por qué lo llaman desaceleración cuando quieren decir crisis? Buena parte del debate económico de los últimos meses ha gravitado sobre esa pregunta. José Luis Rodríguez Zapatero quiso zanjar ayer de una vez por todas esa cuestión semántica -"de escaso interés práctico", a juicio del presidente del Gobierno- con un diagnóstico preciso y terminante: "La economía española experimenta una fuerte desaceleración, casi un frenazo". Llegó a citar explícitamente la "crisis" que el Ejecutivo ha convertido en tabú a fuerza de preferir expresiones más livianas». Siendo tan conscientes del fenómeno como parecen, citando incluso términos como tabú o expresiones más livianas, no se entiende, en cambio, por qué en la bajada del titular encontramos lo siguiente: «El presidente admite que la economía crecerá por debajo del 2\% en 2008 », una expresión confusa que esconde, realmente, que la economía no solo descenderá, sino que prácticamente no crecerá. Encontraríamos aquí, por tanto, un uso eufemístico de crecerá, que mediante un matiz positivo intenta esconder el pésimo dato sobre el $2 \%$. Aunque,

\footnotetext{
${ }^{19}$ Desaceleración, pero moderada. (25 de diciembre, 2016). El País. Recuperado de: https:// economia.elpais.com/economia/2016/12/22/actualidad/1482404529_416341.html

${ }^{20}$ Europa Press. (30 de septiembre, 2009). El crecimiento de la economía española se desacelera en el tercer trimestre. El Mundo. Recuperado de: http://www.elmundo.es/economia/2015/09/30/ 560b9b9ae2704e9a6b8b4588.html

${ }^{21}$ Pérez, C. (24 de junio, 2008). Zapatero asume ya la crisis. El País. Recuperado de: https:// elpais.com/diario/2008/06/24/economia/1214258401_850215.html
} 
bajo nuestro punto de vista, no consigue maquillar la realidad, el propósito manipulativo existe, tanto si la expresión ha sido utilizada por Zapatero (y perpetuada por el periodista) como si ha sido creación del propio emisor. Dicho propósito, consiga o no su fin último - hacer ver que la economía será mejor de lo que realmente es-, logra, como hemos dicho, oscurecer el significado de la noticia y por tanto el valor de la misma.

\section{CONCLUSIÓN}

$\mathrm{Al}$ inicio del presente trabajo se estableció un objetivo claro, el de determinar, mediante el análisis de un corpus de eufemismos, si este proceso contribuye, en mayor o menor medida y según su utilización, a la manipulación lingüística y, a su vez (y precisamente por ello) al oscurecimiento significativo de la noticia. Un oscurecimiento que tendría como consecuencia o bien una mala comprensión del texto, o bien una interpretación manipulada del mismo.

Aplicando para ello la metodología del análisis del discurso y del análisis crítico del discurso, el estudio del corpus ha confirmado que el eufemismo, utilizado como instrumento de manipulación, consigue el propósito que los que recurren a él se proponen: manipular lingüísticamente tanto la realidad, como el referente, como al individuo. Dicha manipulación se lleva a cabo, como se ha indicado a lo largo del corpus, oscureciendo el sentido de la noticia mediante los procesos eufemísticos y, además, apoyándose en toda una serie de recursos que duplican el efecto del eufemismo: despersonalización, omisión del sujeto agente, etc. Este oscurecimiento del sentido puede tener dos efectos: el primero, que el receptor no entienda la noticia o no la intérprete de manera correcta debido a su falta de claridad; el segundo, que el lector extraiga, tras la lectura del texto, conclusiones que, de habérsele informado debidamente, no habría extraído. En cualquiera de los dos casos tiene lugar la manipulación, pues debido al uso lingüístico malintencionado el receptor debe hacer un esfuerzo de procesamiento mayor para entender en toda su extensión la noticia, si es que consigue llegar a ese punto.

Por último, queremos señalar los límites del presente trabajo, que dada la extensión y naturaleza del mismo y la complejidad del tema tratado, no son pocos. Unos límites, no obstante, que pueden constituirse en perspectivas futuras de estudio del tema. Dos de los más destacados, a nuestro parecer, son el proceso cognitivo a través del cual se produce la manipulación y el papel del receptor en todo este proceso. Sería interesante, en el primero de los casos, realizar un análisis pormenorizado del proceso cognitivo que tiene lugar desde que el receptor lee la noticia hasta que, a través del eufemismo y del resto de mecanismos señalados, queda manipulado por ella. En el segundo caso, un estudio que se centrara en el receptor y pusiera de relieve la posibilidad de su papel activo, sería clarificador e incluso necesario, pues supondría un paso más en la creación de una sociedad alerta ante la manipulación. 


\section{REFERENCIAS BIBLIOGRÁFICAS}

ALBELDA, M. (2010) «Atenuación, eufemismos y lenguaje políticamente correcto», Aleza, M: Normas y usos correctos en el español actual, págs. 341-374.

BENVENISTE, E. (1979): «Euphémismes anciens et modernes», Problèmes de linguistique générale, Vol. I, págs. 308-314. Paris: Gallimard

BRUNEAU, Ch. (1952): «Euphémie et euphémisme» VV.AA., Festgabe Ernst Gamillscheg, Tubing: Max Niemeyer, págs. 11-23.

CALSAMIGLIA, H. y TUSÓN, A. (2012): Las cosas del decir. Barcelona: Ariel.

CASAS, M. (1986): La interdicción lingüistica: mecanismos del eufemismo y disfemismo. Cádiz: Servicio de publicaciones, Universidad.

FUENTES, C. y ALCAIDE, E. (2007): La argumentación lingüistica y sus medios de expresión. Madrid: Arco Libros.

GALLUD, E. (2005): «El eufemismo como instrumento de manipulación social», Comunicación y hombre, no. 1, págs. 120-129.

GRICE, P. (1975): «Logic and conversation», en Syntax and Semantics, Vol. 3, Speech Acts. Nueva York: Academic Press, págs. 45-47.

GRIJELMO, A. (2008): El estilo del periodista. Madrid: Taurus.

GUITART, M. (2005): Discurso parlamentario y lenguaje políticamente correcto. Madrid: Congreso de los Diputados.

LÁZARO CARRETER, F. (1974): Diccionario de términos filológicos, $3^{\text {a }}$ ed. Madrid: Gredos.

LÁZARO CARRETER, F. (1990): «El idioma del periodismo, ¿lengua especial?)》, Asterisco, no. 2.

MONTERO, E. (1981): El eufemismo en Galicia: [su comparación con otras áreas romances]. Santiago de Compostela: Universidade de Santiago de Compostela.

MUNTEANO, M. (1953): «Les implications esthétiques de l'euphémisme en France au XVIII siècle», Cahiers de l'Association Internationale des Etudes françaises, no. 3-4-5, págs. 153-166.

NÚNEZZ CABEZAS, A. (2001): «El eufemismo y las fórmulas de evasión en el lenguaje político español», Isla de Arriarán, no. XVII, págs. 419-428.

RODRÍGUEZ GONZÁLEZ (1991): Prensa y lenguaje politico. Madrid: Ed. Fundamentos

SECO, M. (2002): «La manipulación de las palabras» Boletín del Instituto de Estudios Giennenses, no. 180, págs. 7-18

SENABRE, R. (1971): «El eufemismo como fenómeno lingüístico» Boletín de la Real Academia Española, no. 51, págs. 175-189.

VAN DIJK, T. (2009). Discurso y poder. Barcelona: Gedisa. 
ZUMTHOR, P. (1953): «Euphémisme et rhétorique au Moyen Age» Cahiers de l'Association Internationale des Etudes françaises, no. 3-5, págs. 177-184.

Fecha de recepción: 18 de mayo de 2018 Fecha de aceptación: 2 de octubre de 2018 